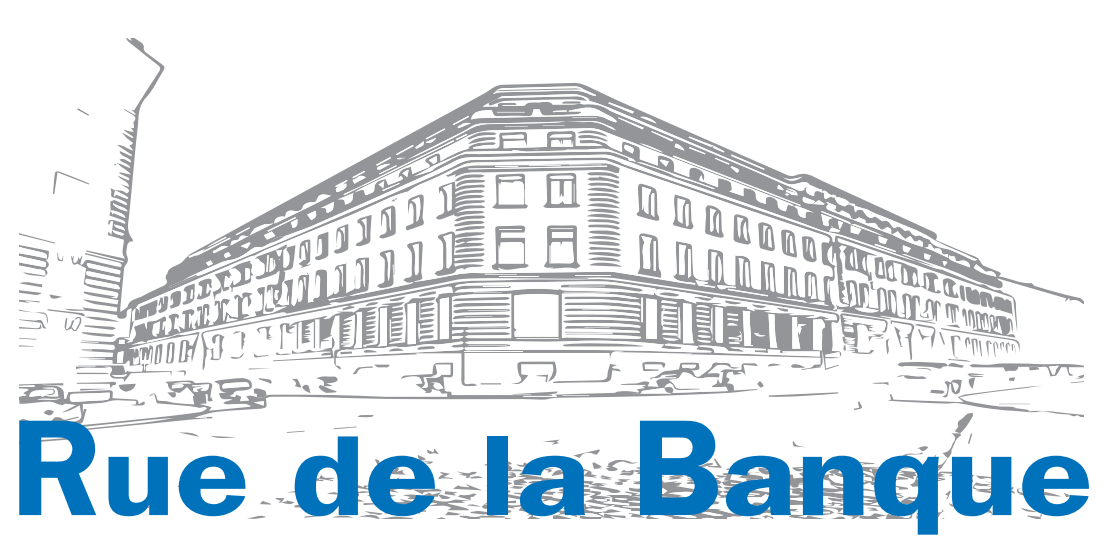

No. 44 May 2017

\title{
Explaining the recent slump in investment: the role of expected demand and uncertainty
}

\author{
Matthieu Bussière \\ Laurent Ferrara \\ Banque de France \\ Juliana Milovich \\ Université Paris Nanterre
}

\begin{abstract}
The weakness in business investment in several advanced economies since the global financial crisis has prompted debate over the main drivers behind this trend and the possible policy responses, if any. This Rue de la Banque summarises an empirical investigation of the main determinants of business investment since 1995 for a panel of twenty-two advanced economies. In the short term, while measures of capital cost seem to play a modest role, low expected demand explains most of the weakness in business investment, with uncertainty also making a contribution. However, systematically over-optimistic GDP growth forecasts from 2008 to 2014 have paradoxically supported business investment.
\end{abstract}

\section{Stylised facts}

In the wake of the global financial crisis, total private investment has been particularly sluggish in advanced economies: the year-on-year growth rate barely reached $2.1 \%$ between 2010 and 2014, compared with 3.3\% in the pre-crisis period (i.e. between 1997 and 2006). This is especially surprising as one would have expected a strong rebound following the 2008-09 financial crisis, when investment fell sharply (contracting by $2.6 \%$ in 2008 and by $11.1 \%$ in 2009). Some of the weakness can be accounted for by residential investment, following the exuberance of the housing markets in the run-up to 2008. However, business investment has also been particularly sluggish: in volume terms, it fell in advanced economies between 2008 and 2014, and in 2014 was around 20\% lower than pre-crisis forecasts (IMF, 2015).

Among advanced economies, euro area countries, especially those in the periphery, have been the most negatively impacted. Chart 1 shows the evolution of real private non-residential investment between Q1 1995 and Q2 2016 (Q1 2009 being equal to 100) for the United States, France, Germany, the United Kingdom and Japan. Our first observation is that all countries experienced a large drop in business investment during the 2008-09 global financial crisis; however, there is also significant heterogeneity as regards the pace of recovery as of 2009 or 2010 . Only the United States and United Kingdom have seen persistently strong rates of growth, leading to a full recovery in business investment in the sense that the level of investment in Q2 2016

C1 Real private non-residential investment between Q1 1995 and Q4 2014 (selected economies) (Q1 2009=100)

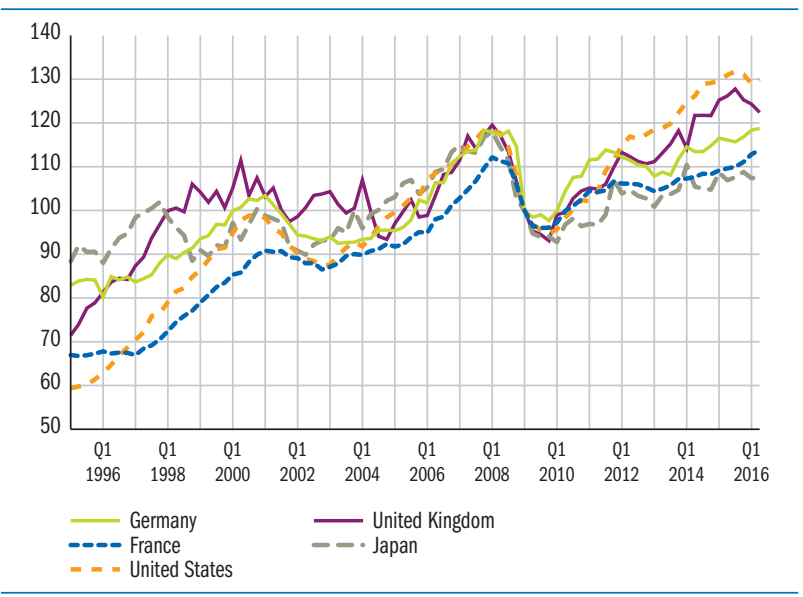

Source: $O E C D$. 


\section{Rue de la Banque}

No. 44 May 2017

is higher than in 2007. One particularly striking feature is the rather flat growth rate for investment in Japan, France and Germany during the recovery, when it would have been reasonable to expect a strong bounce-back after the sharp fall recorded during the global financial crisis.

\section{Why is business investment so low?}

The weakness in business investment is a particular concern as it has a strong influence on potential economic growth.

The persistent weakness in business investment in several advanced economies has revived interest in investment models and prompted discussions over the main drivers behind the trend and over what the policy response should be, if any. The first cause is that aggregate demand has been weak since 2008 , which clearly does not provide strong incentives for firms to invest. Indeed, economic theory places significant emphasis on the accelerator approach that has been widely applied when dealing with business cycle analysis. The simple accelerator principle assumes that the level of desired capital stock is proportional to the level of output. Under this hypothesis, the investment slump may simply reflect the weakness in aggregate demand and does not necessarily require a response that is aimed specifically at investment. Looking forward, investment may rebound as the global recovery takes hold, helped by the exceptionally accommodative policies put in place in key economic regions. However, other explanations should not be neglected. One of these is uncertainty. The role of uncertainty in determining investment was put forward by Bernanke as early as 1983, and the theme has been further developed recently by Bloom et al. (2007) and Bloom (2014). In particular, substantial uncertainty may discourage firms from investing now and lead them to postpone investment decisions. Financial constraints may also have played a role, as the global financial crisis has reduced the supply of credit to businesses. If these frictions are strong, they may delay the recovery in investment (and, as a consequence, in the global economy). This may apply in particular to Europe, where financing conditions have been altered substantially for so-called "periphery" economies.

This Rue de la Banque presents an empirical investigation of the main determinants of annual business investment growth for a set of twenty-two advanced economies over the period 1995-2014, using a panel estimation approach (see Bussière, Ferrara and Milovich, 2015). Our main innovation is that we use vintage macroeconomic one-year-ahead forecasts of GDP growth as a measure of expected demand and we integrate those measures into augmented accelerator models, together with various measures of uncertainty and of financial constraints. Given that the model is not a structural one, we performed various robustness checks to verify our results, notably taking into account a large number of different measures for expected demand (expected domestic GDP growth, global demand, fiscal stance, etc.), for uncertainty (volatility measures, the Economic Policy Uncertainty index put forward by Baker, Bloom and Davis, 2016, disagreement among forecasters stemming from the Consensus Forecasts, index of news, etc.) and for the user cost of capital. ${ }^{1}$

\section{Main results}

The first key result is that the forward-looking demand variable goes a long way towards explaining the trend in investment, and improves upon other existing approaches. This result is robust to alternative measures of expected demand such as external or domestic demand. Second, the results suggest that uncertainty also plays a role in explaining the weakness in investment. Obviously, uncertainty is not directly observable and various measures have been put forward recently in the empirical literature. Our findings show that the level of uncertainty as measured by the historical volatility of stock returns, as well as by the VIX index (which is a measure of the implied volatility of S\&P 500 index options and increases in line with uncertainty on financial markets), seems to have a significant impact on investment decisions, while there is less clear evidence using alternative measures of macroeconomic uncertainty. Moreover, our results also highlight that financial constraints, as measured by the real user cost of capital, do not seem to play a major role in influencing business investment for the countries taken as a whole (although our country-by-country decomposition provides slightly more qualified results for some countries, in particular those of the so-called euro area "periphery"). This result appears to be robust to alternative measures of financial constraints and to a battery of robustness checks.

When trying to disentangle the contributions of the various determinants of business investment growth in the short run since the global financial crisis, the main finding that comes out of the analysis is that the business

1 The measure of user cost of capital is a function of the real interest rate, the depreciation rate and the relative price of investment goods. 


\section{Rue de la Banque}

No. 44 May 2017

C2 Aggregated contributions to business investment growth estimated using the benchmark forward-looking model

(in \%)

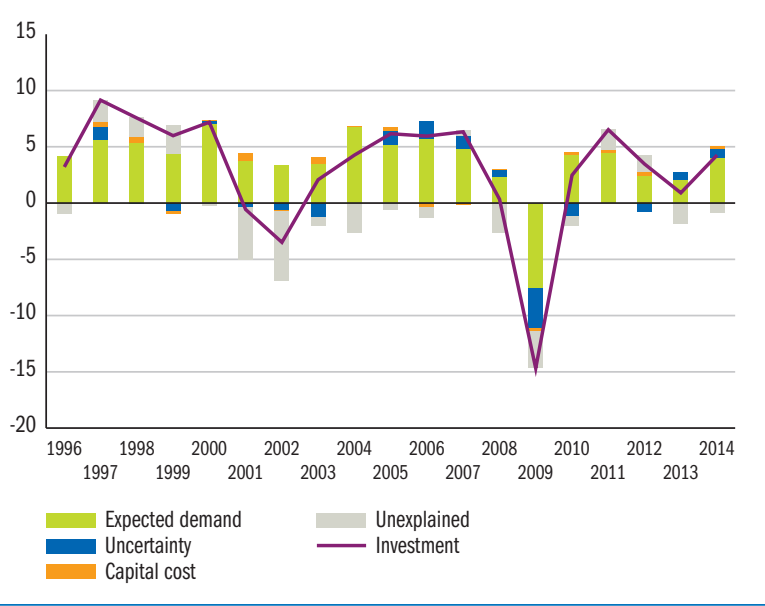

Source: Authors' calculations.

investment slowdown in our panel of advanced economies is mainly due to expected demand (negative contribution of more than $80 \%$ ), while uncertainty has also played a role (negative contribution of $17 \%$ ). By contrast, capital costs do not contribute very much to this drop for the countries taken as a whole (see contributions in Chart 2).

\section{References}

Baker (S.), Bloom (N.) and Davis (S.) (2016)

"Measuring Economic Policy Uncertainty", The Quarterly Journal of Economics, Vol. 131(4), pp. 1593-1636.

Bernanke (B. S.) (1983)

"Irreversibility, Uncertainty, and Cyclical Investment", The Quarterly Journal of Economics, Vol. 98 (1), pp. 85-106.

Bloom (N.) (2014)

"Fluctuations in Uncertainty", Journal of Economic Perspectives, Vol. 28(2), pp. 153-176.

Bloom (N.), Bond (S.) and Van Reenen (J.) (2007) "Uncertainty and Investment Dynamics", Review of Economic Studies, Vol. 74, pp. 391-415.

Bussière (M.), Ferrara (L.) and Milovich (J.) (2015)

"Explaining the Recent Slump in Investment: the Role of Expected Demand and Uncertainty", Working Paper No. 571, Banque de France.
A final consideration worth underlining in the context of our forward-looking model is that forecast errors have actually supported investment since the onset of the crisis. Indeed, if GDP forecasts had been perfect and not systematically over-estimated, our estimates suggest that investment would have been around 12 percentage points lower. As GDP growth forecasts were over-optimistic from 2010 to 2014 , investors who base their decisions on official output forecasts would likely have invested less if they had known how weak global growth was really going to be.

From a policy perspective, our empirical results underline the importance of expected aggregate demand as a key driver of business investment. Thus, economic policies aimed at boosting expected demand are the most effective tool for stimulating investment. Having said that, the role of the other factors should not be neglected. The cost of capital seems to play a more modest role for most countries, but our country-by-country decomposition reveals that it did make an important contribution in some euro area periphery countries. Uncertainty also seems to play a role. Reducing global uncertainty should lead to additional investment growth, in line with economic theory. One possible issue to highlight, however, is that uncertainty is a concept that can take various forms and the channels through which it can be reduced are not entirely clear and need further academic research.

International Monetary Fund (2015)

"Private Investment: What's the Holdup?", World Economic Outlook, Washington, Chapter 4, pp. 71-113, April.

$\begin{array}{ll}\begin{array}{l}\text { Published by } \\ \text { Banque de France }\end{array} & \begin{array}{l}\text { Production } \\ \text { Press and Communication Department }\end{array} \\ \begin{array}{l}\text { Managing Editor } \\ \text { Marc-Olivier STRAUSS-KAHN }\end{array} & \begin{array}{l}\text { May } 2017 \\ \text { www.banque-france.fr }\end{array} \\ \begin{array}{l}\text { Editor-in-Chief } \\ \text { Françoise DRUMETZ }\end{array} & \end{array}$

